\title{
Severity Analysis of Problems Faced by Maize Growers in Punjab
}

\author{
Yugraj Singh and Baljinder Kaur Sidana*
}

Department of Economics and Sociology, Punjab Agricultural University, Ludhiana-141004, Punjab, India

*Corresponding author: baljindersidana@gmail.com

\begin{abstract}
The area under maize crop has been consistently decreasing in the Punjab state over the last few decades, despite its multiple uses. Ineffective implementation of price policy along with certain problems, the maize growers could not earn remunerative returns form maize cultivation in the state. The present study was designed to highlight the various problems in the context of production and marketing front of maize crop in the Punjab state. The data with respect to various problems being faced by the maize growers were collected through well structured pre-tested schedule. The data recorded on scales and severity analysis was carried out by using mean rank score. Garret ranking technique was applied to extract the important problems that influence the maize cultivation in the Punjab state. The severity analysis indicated that among biotic constraints, the emergence of diseases (mean score=1.82) was reported as the most severe problem faced by the maize growers. Plant protection measures being adopted by the maize growers for effective control of insect, pest and management of diseases could increase the production cost of maize. Based on the value of mean score, shortage of labor supply during peak season (mean score $=2.82$ ) was the most important problems amongst abiotic problems, while the intensity of the problems like price variability, shortage of farm machinery was moderately high in the study area. Low price of the produce was exposed as the most influential problem by applying Likert scale. Shortage of labour supply during peak season, emergence of diseases, insect-pest attack and weeds infestation were exposed as moderately severe problems. Hence, the effective and suitable measures to address the highlighted problems of maize could provide impetus to increase maize acreage in the Punjab state.
\end{abstract}

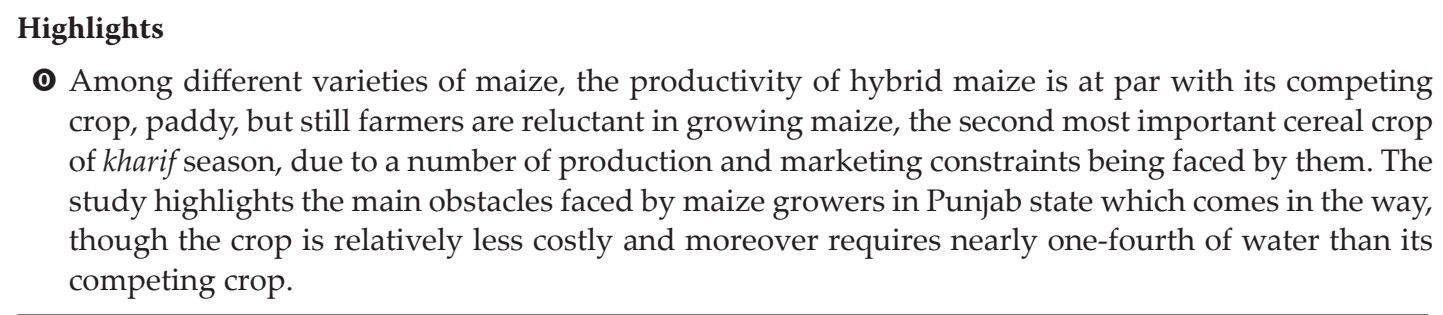

Keywords: Maize, Mean Score, Severity Analysis, Problems, Garret ranking technique

Maize (Zea mays) is one of the most important cereal crop worldwide; not only for human consumption but also for animal consumption. The crop is an important staple food for more than 1.2 billion people in Sub-Saharan Africa and Latin America and a key food crop in Asia. Globally what makes maize a popular crop from cultivation point of view, is its versatility in terms of its suitability to diverse agro-climatic zones offering highest genetic yield potential amongst other cereal crops. Maize is used for myriad purposes ranging from both human and animal consumption to industrial use. As demand for maize is growing globally due to its multiple uses for food, feed and industrial sector, we need to produce more from same or even less resources (DMR, 2013). As per recent estimates, about 1040 million tonnes of maize has been produced on 185 million hectares of area in the world. Maize was cultivated on 4.49 per cent of total cropped area in the year 2015-16 and produced approximately 


\section{C) Singh and Sidana}

21.81 million tonnes of maize, making this crop as third most important food grain after wheat and rice. It contributes nearly 9 per cent to the national food basket and more than ₹ 400 billion to the agricultural GDP besides generating employment to 1000 million man-days in the farm and downstream agricultural and industrial sectors. The maize is cultivated throughout the year in all states of the country for various purposes including grain, fodder, green cobs, sweet corn, baby corn and pop corn. The predominant maize growing states that contributes more than 80 per cent of the total maize production are Karnataka (14.99\%), Madhya Pradesh (11.83\%), Bihar (10.99\%), Tamil Nadu (10.93\%), Telangana (7.96\%), Maharashtra (6.93\%), Andhra Pradesh (6.48\%), Uttar Pradesh (5.76\%) and Rajasthan (5.55\%). Apart from these states maize is also grown in Jammu and Kashmir and NorthEastern states (GOI, 2016).

Punjab unlike the rest of India had traditionally been a maize growing state until rice became popular. Area under maize cultivation declined since 2006-07 with little improvement in the yield. The maize production in Punjab in 2014-15 was 0.42 million tonnes, and the total area under the crop was 0.12 million hectares. With an average productivity of $3,687 \mathrm{~kg} / \mathrm{ha}$, farmers cultivating maize made substantial profits that year. With in Punjab the primary maize producing areas are Hoshiarpur, Roopnagar, Nawan Shahar, Kapurthala, Ropar and Amritsar (Anonymous 2016). In Punjab, the maize is sown normally during the end of May to end of June and is harvested in the months of SeptemberOctober. A number of efforts were made to bring about technological breakthrough in this crop. In spite of this, the area under maize depicted a continuous decline during the Post-green revolution period. The decline in maize-acreage was mainly caused by the advent of HYVs of its competing crop (Singh et al 2012). The predominance of ricewheat rotation in the Punjab state has been leading to many environmental related problems such as the problem of depleting water table, deteriorating soil fertility etc. In wheat-paddy rotation, paddy crop is more resource depleting than wheat crop and inefficiencies in its production are larger in the case of the small farmers (Kataria and Melkani 2014). Paddy crop is highly water intensive crop, as it consumes 3000 litres of water to produce one kilo of rice (Saran et al. 2013). Thus, the sustainability of agriculture in state is under threat. In order to revitalize Punjab agriculture through exploring alternatives to the rice-wheat system, various expert committees and other have recommended the diversification of agriculture towards highvalue commodities and a broader mix of traditional commodities and agro-processed products that augment farm income, promote exports and conserve soil and water resources. Underlying the importance of diversified agriculture, it has been observed that the Punjab state has large potential for cultivation of a variety of high value crops as well as related enterprises (Johl Committee, 2002). Recently, Punjab government has submitted a diversification plan to the Union government for shifting 12 lakh hectares of paddy area to other crops like maize, cotton, sugarcane, agro-forestry, pulses, fruits and vegetables in the kharif season groups. For this purpose, the funds demanded by the State Government from Union Government are worth about $₹ 5000$ crores. Maize is one of the best alternate crop, as the profits in Maize-Potato-Wheat rotation comes after Paddy-Potato-Wheat rotation (Kaur and Kaur 2012).

In 1970-71, the area under maize cultivation was approximately 5.55 lakh hectares, but ever since, this area has been continuously declining. The agricultural policy reflects the potential of maize crop as the future crop of Punjab, becoming the most suitable replacement for paddy. The maize cultivation in the state is facing certain constraints which have proved detrimental to the growth of maize crop in Punjab. It has been found that cost of cultivation of maize is lower than the rice in the state but productivity of maize could not keep pace with the productivity of rice. In the back drop of this, the present study is initiated to examine the various problems faced by the maize growers during its cultivation. The Punjab state has targeted towards other crops to maintain ecological balance and to save the depleting water table as well as soil condition of the state. Market malpractices, high cost of storage facilities, few processing industries are the main constraints of maize growing farmers in the state. An attempt has also been made to identify the production and marketing constraints, which hinder the growth of maize crop in the state. 


\section{MATERIALS AND METHODS}

The present study was conducted in Punjab state during the year 2014-15.. Multi-stage sampling technique was followed for the selection of the study sample. At the first stage, two districts with highest concentration of area under maize crop for the year 2014 was selected namely Hoshiarpur and Roopnagar. At the second stage two blocks from each district were selected following the same criterion. Garhshanker and Banga blocks were selected from Hoshiarpur district and Shri Anandpur Sahib and Noorpur Bedi blocks were selected from Roopnagar district respectively. At third and last stage, a sample of 100 maize growers ( 25 from each selected block) was randomly selected. A comprehensive schedule was developed for the collection of data with respect to various problems being faced by the maize growers while production and marketing of maize. More comprehensive techniques like one sample t-test and garret ranking techniques were used in order to draw significance inferences of the data. Methodological framework of these techniques is given as under:

\section{Likert Scale}

Three point Likert scale was used to assess the severity of problems being faced by the sample growers for producing and marketing of maize. It was developed by Rensis Likert, an American social psychologist. It is a most widely used approach to scaling responses in survey research and following scale were used:

\begin{tabular}{cc}
\hline Severity of problem & Scale \\
\hline Normal & 1 \\
Moderate & 2 \\
Severe & 3 \\
\hline
\end{tabular}

\section{Mean score}

Mean score representing the mean level of severity of problems being faced by the maize growers. It is calculated by using following formula,

Mean score $=\frac{\sum\left(1 * f_{\text {normal }}+2 * f_{\text {moderate }}+3 * f_{\text {severe }}\right)}{100}$

Where,

$f_{\text {normal }}=$ frequency of farmers reported as 'normal' response in favour of severity of problem $f_{\text {moderate }}=$ frequency of farmers reported as 'moderate' response in favour of severity of problem

$f_{\text {severe }}=$ frequency of farmers reported as 'severe' response in favour of severity of problem

The results are interpreted on the basis of the value of mean score. More is the value of mean score more sever is the problem and vice-versa.

\section{One sample t-test}

The level of severity of problems being faced by each individual maize grower supposed to be varied significantly in the sample. In this regard, one sample t-test was used to test significance of severity of problems to be reported by the sampled farmers. The null and alternative hypothesis was given as under:

Null Hypotheses $\left(\mathrm{H}_{0}\right)$ : Mean score of severity of problems faced by the sampled maize growers with respect to various production and marketing problems do not vary significantly in the sample (Test score are equal)

Alternative Hypotheses $\left(\mathbf{H}_{\mathbf{1}}\right)$ : Mean score of severity of problems faced by the sampled maize growers with respect to various production and marketing problems do vary significantly in the sample (Test score are unequal).

The form of the model is given below:

$$
T-T e s t=\frac{\bar{X}-\mu}{\sigma \sqrt{n}}
$$

Where,

$$
\begin{aligned}
& \bar{X}=\text { Sample mean } \\
& \mu=\text { Population mean } \\
& \sigma=\text { Standard deviation } \\
& \mathrm{n}=\text { no of respondents }
\end{aligned}
$$

\section{Garret Ranking Method}

This is another technique to extract the most important problem that influences the maize production. The responses of the sample maize growers with respect to various problems were assessed by assigning rank score. In this method, the farmers were asked to rank the given problem from 1 to 8 according to the severity of the problem 
C) Singh and Sidana

i.e. 1 for most important problem and 8 for least important problem. The orders of merit given by the respondents were converted into ranks by using the following formula:

Percentage Position $=\frac{100\left(R_{i j}-0.5\right)}{N}$

Where,

$R_{i j}=$ Rank given for $i^{\text {th }}$ item $j^{\text {th }}$ individual

$N_{j}=$ Number of items ranked by $j^{\text {th }}$ individual.

The percentage position of each rank thus obtained was converted into scores by referring to the table given by Henry Garret. Then for each factor the scores of individual respondents were added together and divided by the total number of respondents for whom the scores were added. The mean scores for all the factors were arranged in the order of their ranks and inferences were drawn.

\section{RESULTS AND DISCUSSION}

Among cereals, maize is the third most important crop after wheat and paddy in the Punjab state. Maize crop has strongly been recommended by many expert committees to be the part of diversification plan due to its nature of low intake of natural resources. In spite of cost-effective, the area under this crop has been declining consistently due to certain problems being faced by maize growers. The findings of the present study and their relevant discussion have been summarized under the following heads:

\section{Severity analysis of problems faced by maize growers}

Sample maize growers have reported many production and marketing constraints which hamper the production and affects the marketing pattern of maize in the study area. Depending upon the nature of problems, all the constraints faced by the maize growers are further classified into biotic and abiotic constraints. As discussed in the methodology, a three-point Likert scale was used to find out the severity of the constraints, all the sample farmers were asked to give number to each constraint i.e. 1 for normal, 2 for moderate and 3 for severe problem. Results were interpreted on the basis of mean score and the constraint with highest mean recognized as the severe problem.

Among the different biotic constraints (Table $1)$, emergence of diseases emerged as the most important problem as the mean score (1.82) was the highest in this case. Rust (Puccinia sorghi), stalk rot (Physoderma maydis) and storage rots (Aspergillus $s p p$.) were the common diseases reported in the sample districts. As reported by the maize growers, attack of insect-pest and weeds infestation was some of the other important constraints which discourage the cultivation of maize crop in the study area. The value of mean score came out to be 1.70 and 1.52 in favour of these problems. The calculated value of t-statistics is very high than that of table value which further revealed that mean score of severity of problems faced by the sampled maize growers with respect to biotic constraints vary significantly in the sample. The maize growers were used to follow many plant protection measures to control the attack of insect pests, emergence of diseases and weeds in the study area. As reported by the growers, high price of plant protection measures increases the production cost of maize which ultimately led to lower net returns from maize and thus was one of the major hurdle in maize production.

Table 1: Constraints in the production and marketing of maize in Punjab, 2014-15

\begin{tabular}{|c|c|c|c|}
\hline Constraints & $\begin{array}{c}\text { Mean } \\
\text { score }\end{array}$ & $\begin{array}{c}\text { Standard } \\
\text { Deviation }\end{array}$ & t-value \\
\hline \multicolumn{4}{|c|}{ Biotic Constraints } \\
\hline Diseases & 1.82 & 0.39 & $4.66^{*}$ \\
\hline Insect-Pest & 1.70 & 0.46 & $6.51^{*}$ \\
\hline Weeds & 1.52 & 0.50 & $9.56^{*}$ \\
\hline \multicolumn{4}{|c|}{ Abiotic Constraints } \\
\hline Shortage of labour & 2.83 & 0.37 & $21.98^{*}$ \\
\hline Price variability & 2.82 & 0.39 & $21.24^{*}$ \\
\hline $\begin{array}{c}\text { Non-availability of good } \\
\text { quality Inputs }\end{array}$ & 2.76 & 0.43 & $17.71^{*}$ \\
\hline $\begin{array}{c}\text { Non-availability of } \\
\text { machines }\end{array}$ & 2.66 & 0.47 & $13.86^{*}$ \\
\hline Low market demand & 2.46 & 0.50 & $9.18^{*}$ \\
\hline Storage of grains & 2.42 & 0.50 & $8.47^{*}$ \\
\hline Marketing problem & 2.41 & 0.49 & $8.29^{*}$ \\
\hline Environmental constraints & 2.41 & 0.49 & $8.29^{*}$ \\
\hline $\begin{array}{c}\text { Difficult to access } \\
\text { information on price }\end{array}$ & 1.18 & 0.39 & $21.24^{*}$ \\
\hline Lack of grading facility & 1.12 & 0.32 & $26.94^{*}$ \\
\hline $\begin{array}{c}\text { Not aware of grading } \\
\text { structure }\end{array}$ & 1.06 & 0.24 & $39.38^{*}$ \\
\hline
\end{tabular}

* Significant at one per cent level of significance. 
As revealed from Table 1, the mean score was the highest in case of shortage of labour (2.83) and hence, the shortage of labour supply during peak season has emerged as the major problem as perceived by the sample growers. Intensive labour is being used for maize cultivation as most of the operations are manually operated. Harvesting and threshing covers near 80 per cent of the total human labour used in maize cultivation and these operations are being performed by migrant labourers.

As reported by the sample farmers, due to shortage of migrant labourers at the time of harvesting and threshing, the wage rate shoot up and thus cost goes up. The farmer has to bear burden of high harvesting costs due to demand-supply gap in which less supply of labour and more demand leads to increase in wage rate. The migrant labourers charge near about ₹ 10000 to ₹ 11000 per hectare for harvesting maize crop depending upon the labour availability during peak period. The second major problem faced by the farmers was price variability in maize crop with mean score of 2.82 (S.D=0.39). The price of the maize grain mainly depends upon the moisture content present in it. Price is negatively related with the moisture, means more moisture fetches less price and less moisture fetches more prices. Price is directly related with the moisture content, the grain having the optimum moisture i.e. $\leq 13.50$ per cent, is considered best for marketing, but the farmers in the sample study was not much aware of this thing.. The third major constraint was non-availability of quality inputs as mean score in this regard came out to be 2.76 (S.D=0.43). In lieu of getting more profit margin, most of the pesticides dealers have been promoting and selling sub-standard inputs in study area. Additionally, operational efficiency of farm is greatly influenced by the availability of farm machinery as well. Shortage of machinery and equipment is another important problem reported by maize growers.

Other important problems faced by the maize growers were low market demand, low storage capacity of grains, low output price, environmental constraints, lack of grading facilities and unaware of the grading structure. The calculated value of t-statistics is very high than that of table value which further revealed that mean score of severity of problems faced by the sampled maize growers with respect to all abiotic constraints vary significantly in the sample. Hence, there is an urgent need to address these problems to promote area under maize cultivation. The constraint analysis the marketing of maize reflects the urgent need for overhauling of the entire maize marketing system in the state. This in turn would help in the allocation of more resources to maize crop. This will go a long way to squeeze out some areas from rice that would provide impetus to much publicized diversification programme of government and also attain the increase in maize production (Chahal and Kataria, 2010).

\section{Problems faced by sample maize growers in Punjab}

Garret-ranking technique is another analytical technique to extract the most significant problem which influences the maize cultivation. As per this method, respondents have been asked to assign the rank for all the problems and the outcome of such ranking has been converted into score value. First rank given to the problem with the highest mean score and lowest rank given to the minimum mean score (Table 2).

Table 2: Ranking of problems faced by sample maize growers in Punjab, 2014-15

\begin{tabular}{ccc}
\hline Problems & $\begin{array}{c}\text { Garret Mean } \\
\text { Score }\end{array}$ & Rank \\
\hline Low Price & 7.90 & I \\
Shortage of labour supply & 5.71 & II \\
Disease & 5.67 & III \\
Insect-pest attack & 5.63 & IV \\
Weeds & 5.31 & V \\
Environmental Problems & 3.91 & VI \\
Marketing Problems & 3.38 & VII \\
Lack of processing units & 2.36 & VIII \\
\hline
\end{tabular}

Among the different problems faced by maize growers, highest mean score was assigned to low price of maize crop (7.90) and placed at first rank. An average price received by the farmer was only ₹ 1070 per quintal which was very low than that of MSP of maize (₹ 1310 per quintal) during the 2014-15. Shortage of labour supply during peak season is the second important problem as reported by the sampled growers. Stalk rot and rust were the common diseases in the sample area. The mean score with respect to the problems such as 


\section{C) Singh and Sidana}

emergence of diseases, insect-pest attack and weeds infestation came out to be 5.67, 5.63 and 5.31 and placed at III, IV and V rank. Though the other problems like environmental issues, marketing problems and lack of processing units were the least important problems, but these also play influential role on maize production in the Punjab state.

\section{CONCLUSION}

An exhaustive severity analysis of constraints faced by the maize growers revealed that emergence of diseases (in case of biotic constraints) and shortage of labour (in case of abiotic constraints) were most severe problems in the study area. Based on the value of mean score, the intensity of the problems like price variability, shortage of farm machinery was moderately high, while the prevalence of problems like non-availability of quality inputs, low market demand, storage of grains, marketing problems and environmental constraints was fairly moderate, however, the problems such as difficult to access information on price, lack of grading facilities and not aware of the grading structure were the least important problems. Low price of the produce was exposed as the most influential problem by applying Garrett ranking technique. Shortage of labour supply during peak season, emergence of diseases, insect-pest attack and weeds infestation were exposed as moderately important problems. Based on the outcomes of the study, there is an urgent need of effective implementation of MSP so far sale of maize is concerned. Development of disease resistance varieties, check on sub-standard pesticides, availability of good quality inputs, availability of modern machinery to improve farm efficiency, and development of post harvest technologies (storage facilities, opening up of processing units etc.) were some of the suggestive measure to encourage the maize cultivation in the Punjab state.

\section{REFERENCES}

Anonymous. 2016. Statistical Abstract of Punjab. Economic and Statistical Organization, Government of Punjab.

Chahal, S.S. and Kataria, P. 2010. Constraints in the production and marketing of maize in Punjab. Agric. Update, 5: 228236.

Directorate of Maize Research. 2013. Annual Report 2012-13, Indian Council of Agricultural Research, Pusa Campus, New Delhi.

Government of India. 2016. Agricultural Statistics at a Glance. Ministry of Agriculture \& Farmers Welfare, Department of Agriculture, Cooperation and Farmers Welfare, Directorate of Economic and Statistics, New Delhi.

Johl, S.S. 2002. Agricultural production pattern adjustment programme in Punjab for productivity and growth A Report by Chief Minister Advisory Committee in Agricultural Policy \& Restructuring, Government of Punjab

Kaur, A. and Kaur, P. 2012. Shift in cropping pattern vis-àvis stress on water resources in Punjab. Ind. J. Econ. Dev. 8: 91-98.

Kataria, P. and Melkani, A. 2014. Sustainability of paddywheat rotation in Punjab. Ind. J. Econ. Dev., 10: 313-18.

Saran, S.K., Kataria, P. and Kaur, A. 2013. An electricity energy usage and energy subsidy in Punjab agriculture. Ind. J. Econ. Dev., 9: 199-206.

Singh, N., Rajendran, R.A., Shekhar, M., Jat, S.L., Kumar, R. and Kumar, R.S. 2012. Maize opportunities and challenges. Report by Directorate of Maize Research, New Delhi. 